\title{
Growth of Verticillium tricorpus-A Saprophytic Fungus and Potential Entomopathogen of Cocoa Pod Borer as Affected by the Medium and Light
}

\author{
Leopoldus Libero Baon ${ }^{1}$, Nursamsi Pusposendjojo ${ }^{1}$, Bambang Hadisutrisno ${ }^{1}$ and John Bako Baon ${ }^{2}$ \\ 1. Faculty of Agriculture, Gadjah Mada University, Jl. Flora, Bulaksumur Campus, Yogyakarta 55281, Indonesia \\ 2. Indonesian Coffee and Cocoa Research Institute, Jl. P.B. Sudirman 90, Jember 68118, Indonesia
}

\begin{abstract}
Cocoa pod borer (CPB) has endangered Indonesian cocoa. Use of entomopathogen in biocontrol of pests is considered to be environmentally friendly approach. Verticillium tricorpus has been reported to be a potential agent for controlling CPB. The aim of this research was to study the possibility in using alternative, easy and cheap media and also the role of intensity and quality of light for mass production of $V$. tricorpus. The experiments were laid out in split-plot design as factorial, where every combination treatment was replicated three times. Medium, in form of semi-synthetic and natural, was treated as the main plot, while light as sub-plot. Results of this study showed that for the growth and development of fungus $V$. tricorpus, the use of alternative natural media in form of a mixture of cocoa pod husk and maize was the best. Use of cocoa dextrose agar (CDA) as semi-synthetic medium was more suitable for the growth and development of $V$. tricorpus compared to potato dextrose agar (PDA). The semi-synthetic and natural media consisted of cocoa husk and maize are suitable for cocoa production area in Indonesia, where mostly cocoa is planted in lowland area and mostly is also suitable for corn but not for potato growing. Growth of the fungus colony especially on CDA medium reached its optimum condition when using white light with the intensity of 1,000 lux. This study proved that the requirement for light quality was different between growth and development purposes. Development of $V$. tricorpus until the production of conidia in optimal condition was reached with the use of yellow light with the intensity of 1,000 lux.
\end{abstract}

Key words: V. tricorpus, growth, media, intensity, light quality.

\section{Introduction}

During the 20th century, Indonesian cocoa has been endangered by cocoa pod borer (CPB, Conopomorpha cramerella) two times, firstly in very early 1900's and secondly in late 1990's. In the first period, the pest could be overcome successfully by eradication pruning, whereas in the second period, the eradication pruning cannot be carried out until now due to that the productive cocoa area in Indonesia has reached more than one million ha. Meanwhile, productivity of Indonesian cocoa is still much lower (about $700 \mathrm{~kg} / \mathrm{ha}$ ) compared to its potential productivity (about 2,500 $\mathrm{kg} / \mathrm{ha}$ ). One of the causes of the low productivity is the infestation of CPB which reduces the yield and

Corresponding author: John Bako Baon, Ph.D., research fields: soil fertility, soil biology and plant nutrition. quality of cocoa [1]. Wiryadiputra et al. [2] reported that yield loss due to CPB in Central Sulawesi and West Sumatera reached about $78 \%$. The loss by CPB is the resultant of seed weight decrease, increase in low seed quality and the rising cost of harvesting due to difficulty in separating the affected seeds from cocoa pod husks [3].

The CPB pest attack has penetrated almost throughout the entire area of the cocoa in Indonesia with various attack intensity. The severity of the infestation of the pest in cocoa production centers on CPB in Sulawesi region reached 39\%-79\% [2]. If there are no control measures, it is estimated that over the next 7-10 years, the Indonesian cocoa farm acreage will be throughoutly infested by CPB with a high severity [4]. Therefore, the success of the pest 
control will directly support the sustainability of cocoa production in Indonesia.

In general and easy way, the control of CPB can be carried out by insecticide spraying, just when the CPB attack is minimum $30 \%$ or classified as heavy [5]. However, this type of control is considered to be environmentally unfriendly. By other means, CPB can be controlled by implementing good agricultural practices, such as sanitation of infested pods, frequent harvest, pod sleeving [1], use tolerant clones [6, 7], inducing resistance [8], sex pheromones [9, 10], phytocoater [11] and applying entomopathogen, such as Paecilomyces fumosoroseus [12], Beauveria bassiana [13] and Bacillus thuringiensis [14, 15].

Biopesticide and botanical insecticide technologies in controlling CPB have developed recently. Use of entomopathogen in biocontrol of pests is considered to be environmentally friendly approach. $V$. tricorpus as a saprophyte [16] has been reported to be a potential agent for biocontrol [17], however, there is still no study yet on the use of this fungus as an entomopathogen of CPB. A preliminary study in an attempt to control CPB has been pioneered by one of the authors (Bambang Hadisutrisno) by isolating a fungus $-V$. tricorpus from a dead insect of CPB (Conopomorpha cramerella) obtained from Papua. However, the study on ecophysiology characteristics of $V$. tricorpus, such as its response to growth medium and light types, is still very rare. Meanwhile, this information is indispensable for further study of $V$. tricorpus development. Prajogo and Yusmani [18] have studied viability of Verticillium lecanii in response to the length of sunlight expose. The aim of this research was to study the possibility in using alternative, easy and cheap media and also the role of intensity and quality of light for mass production of $V$. tricorpus.

\section{Materials and Methods}

Inoculum of $V$. tricorpus used in this study was a pure isolate multiplied in Agriculture Mycology
Laboratorium, Faculty of Agriculture, Gadjah Mada University, Yogyakarta. Originally, the isolate was obtained from the preliminary study by the third author after isolating the fungus ( $V$. tricorpus) from a dead insect of CPB (Conopomorpha cramerella) obtained from Papua. Multiplication of this fungus was carried out on slant potato dextrose agar (PDA) media [19] as much as possible. Inoculation of the fungus on all types of media used standard method by cork drill $(0.7 \mathrm{~cm})$ for taking mycelia of the fungus and placed it up side down for optimizing the contact between fungus and media.

The experiments were laid out in split-plot design as factorial, where every combination treatment was replicated three times. Medium, in form of semi-synthetic and natural, was treated as the main plot, while light as sub-plot. Semi-synthetic media used in this study were PDA and cocoa dextrose agar (CDA). Natural media used were ground maize, ground cocoa husk, ground cocoa leaf, mixed ground maize and cocoa husk (1:2), and mixed ground maize and cocoa leaves (1:2). Light treatments consisted of intensity and quality of light. Levels of intensity of light were dark, 1,000 lux and 2,000 lux, respectively, while levels of quality of light were white, yellow and green lights, respectively.

\subsection{Media Preparation}

\subsubsection{PDA Media}

The composition of PDA media were potatoes (200 $\mathrm{g})$, dextrose (20 g), agar (20 g) and distilled water $(1,000 \mathrm{~mL})$. Small potato cuts were placed in a 1,000 $\mathrm{mL}$ Erlenmeyer flask added with the distilled water, then boiled for approximately $30 \mathrm{~min}$. The potato extract was filtered and placed again in a $1 \mathrm{~L}$ Erlenmeyer flask and maintained at $1 \mathrm{~L}$ volume. The agar and dextrose were dissolved in the potato extract by stirring. The mixture was heated again until agar and dextrose really dissolved to form a clear PDA, usually after 30 min boiling time. The hot liquid PDA was then transferred into $100 \mathrm{~mL}$ Erlenmeyer flasks, 
followed by sterilization in an autoclave at a temperature about $121{ }^{\circ} \mathrm{C}$ with one atmospheric pressure for 20 min since it reached the temperature and pressure.

\subsubsection{CDA Media}

Materials needed to make $1,000 \mathrm{~mL}$ CDA media were fresh cocoa fruit husks (200 g), dextrose (20 g), agar $(20 \mathrm{~g})$ and distilled water $(1,000 \mathrm{~mL})$. The procedure to prepare the CDA media was similar with the PDA media, while the difference was only by replacing potatoes with fresh cocoa husks. Extraction of cocoa husk took longer time than that of potato, i.e., $45 \mathrm{~min}$.

\subsubsection{Ground Maize Media}

Ground maize media used corn seeds, which had been milled and then soaked in water for about $12 \mathrm{~h}$. The ground maize was drained until the water content of maize obtained was about 32\%, then about $90 \mathrm{~g}$ ground maize was transferred to $140 \mathrm{~mL}$ botles about two-thirds of the botle. The bottle is then corked with a sterile cotton, wrapped with aluminium foil and then sterilized in an autoclave at a temperature about $121{ }^{\circ} \mathrm{C}$ with one atmospheric pressure for $20 \mathrm{~min}$ since it reached the temperature and pressure.

\subsubsection{Ground Cocoa Husk Media}

Materials used for preparing cocoa husk media were fresh cocoa husks, which were sliced using a chopper (single motor power type slicer JYO9A-4 1/4 HP $50 \mathrm{~Hz}$ ) producing small cuts with approximately $0.3 \mathrm{~cm}$ thickness. The cocoa husk cuts were air-dried in a greenhouse for about $10 \mathrm{~d}$, then grinded with a miller (type Reeves motodrive 221-V2M-18) to produce ground cocoa husk, approximately 20 mesh. The ground cocoa husk was wrapped in muslin and soaked in sterile distilled water for $1 \mathrm{~min}$. After being drained, the ground cocoa husk with water content of about $69 \%$ was used, which then transferred to 140 $\mathrm{mL}$ botles about two-thirds of the botle volume $( \pm 90$ $\mathrm{g}$ of ground cocoa husk). The bottle is then corked with a sterile cotton, wrapped with aluminium foil and then sterilized in an autoclave at a temperature about
$121{ }^{\circ} \mathrm{C}$ with one atmospheric pressure for $20 \mathrm{~min}$ since it reached the temperature and pressure.

\subsubsection{Ground Cocoa Leaf Media}

Materials used to prepare this medium were fallen dry cocoa leaves. After cleaning and cutting into pieces $(0.5 \mathrm{~cm} \times 0.5 \mathrm{~cm})$, the cocoa leaves were wrapped with muslin, and then soaked in sterile distilled water for $1 \mathrm{~min}$. After being drained, the cut cocoa leaves with water content of about $62 \%$ was then transferred to $140 \mathrm{~mL}$ botles about two-thirds of the botle volume ( $\pm 90 \mathrm{~g}$ of ground cocoa husk). The bottle is then corked with a sterile cotton, wrapped with aluminium foil and sterilized in an autoclave at a temperature about $121{ }^{\circ} \mathrm{C}$ with one atmospheric pressure for 20 min since it reached the temperature and pressure.

2.1.6 Mixed Ground Maize and Ground Cocoa Husk Media

Ground maize and ground cocoa husk used were similar with in the previous media. The mixture of ground maize and ground cocoa husk was in composition of 1:2 (w/w). The mixture was transferred to $140 \mathrm{~mL}$ botles about two-thirds of the botle volume ( $\pm 90 \mathrm{~g}$ of ground cocoa husk). The bottle is then corked with a sterile cotton and wrapped with aluminium foil and sterilized in an autoclave at a temperature about $121{ }^{\circ} \mathrm{C}$ with one atmospheric pressure for 20 min since it reached the temperature and pressure.

2.1.7 Mixed Ground Maize and Ground Cocoa Leaf Media

Ground maize and ground cocoa leaf used were similar with in the previous media. The mixture of ground maize and ground cocoa leaf was in composition of 1:2 (w/w). The mixture was transferred to $140 \mathrm{~mL}$ botles about two-thirds of the botle volume ( $\pm 90 \mathrm{~g}$ of ground cocoa husk). The bottle is then corked with a sterile cotton, wrapped with aluminium foil and sterilized in an autoclave at a temperature about $121{ }^{\circ} \mathrm{C}$ with one atmospheric pressure for 20 min since it reached the temperature and pressure. 


\subsection{Medium, Inoculum and Light Treatments}

Multiplication of $V$. tricorpus fungus isolate was conducted as much as possible on PDA culture medium in agar slant tubes and agar Petri dishes to make sure sufficient amount for the need of this study. Fungal inoculation on all medium was done in the same way of general fungi inoculation. Pure isolate of $V$. tricorpus in Petris dish was cut using a hole cork ( $0.7 \mathrm{~cm}$ in diameter) to be transferred in several media tested, which was also placed in Petri dishes. When putting isolate sample, the surface with fungal mycelium was placed in direct contact with the media tested.

On the light intensity treatment, each medium that has been inoculated with the fungal culture was placed on three variations of light intensity, i.e., dark, 1,000 lux and 2,000 lux. For dark condition, the fungal culture with the media tested was put on shelf and closed with black cloth to prevent light entrance. For light intensity treatment of 1,000 lux and 2,000 lux, respectively, used one and two Phillips fluorescent lamps of 20 watt (after being confirmed with luxmeter). The distance between the lamps and the cultures was $15 \mathrm{~cm}$. To ensure the exposed light only come from the fluorescent lamps, around the rack was covered with black linen fabric. Incubation for PDA and CDA media was implemented until there was one of the media have been fully filled with mycelium, while for natural media in the bottle, incubation was carried out till four weeks.

At the light quality treatment, the fungal cultures placed on the shelves were irradiated with three light quality, i.e., white light, yellow light and green light. For this purpose, two Phillips fluorescent bulbs of 10 watt with intensity of 1,000 lux sheathed with two sheets of green Mika paper to get green light (570-590 $\mathrm{nm})$ and two sheets of yellow Mika paper to get yellow light (500-570 nm). White light was obtained from the fluorescent lamps without Mika paper sheet. To ensure the exposed light only come from the fluorescent lamps, around the rack was covered with black linen fabric. Incubation for PDA and CDA media was implemented until there was one of the media have been fully filled with mycelium, while for natural media in the bottle, incubation was carried out till four weeks.

Fungal growth observation was carried out every 2 $\mathrm{d}$ based on diameter of the colonies on CDA and PDA media. The data were then transformed to area of the fungal colony. To calculate the number of conidia formed in each of colony, it was done by making suspension of fungal conidium in the Petri dish by pouring $10 \mathrm{~mL}$ of sterile distilled water. The suspension was put into test tube, and then was vortexed for $1.5 \mathrm{~s}$. At the end of experiment, the fungal conidia density was calculated using hemacytometer from 10 fields of view and number of dilutions. Media that were placed inside the bottle were shaken every $2 \mathrm{~d}$, and every week development of mycelium was observed visually. Calculation of media conidium density in the botles was carried out as similar with those in Petri dish. Analysis of variance was used to analyze effects of media and light on fungal growth rate and conidia density [20]. Duncan multiple range test at the $5 \%$ was used; when there was significant difference between the treatments, then the test conducted. All statistical analyses were performed using the SPSS computer programs.

\section{Results and Discussion}

Influence of synthetic media and light intensity on growth development of $V$. tricorpus in CDA media and PDA is presented in Fig. 1. From these data, it can be seen that growth of $V$. tricorpus was better on CDA media than on PDA. By using the two synthetic media, it is known that for $V$. tricorpus grown on CDA medium with light intensity of 1,000 lux, the growth of its mycelium covered almost entire surface of the media in the first $8 \mathrm{~d}$ after incubation. The mycelium growth rate in that condition was $11.1 \mathrm{~mm} / \mathrm{d}$, followed by CDA medium with light intensity of 2,000 lux, 
whereas the fungal growth on other medium treatments was less. The fungus grown on PDA medium with light intensity of 2,000 lux had the lowest mycelium growth rate $(4.6 \mathrm{~mm} / \mathrm{d})$. This result indicates that the use of CDA as semi-synthetic medium was more suitable for the growth and development of $V$. tricorpus compared to PDA. Fig. 2 shows that the growth of $V$. tricorpus was more vigorous in CDA median than in PDA both under 1,000 lux light intensity and under yellow light quality.

From Table 1, it can be noted that there is interaction between synthetic media with light intensity. Conidia density of $V$. tricorpus was higher in CDA media than in PDA media, only when light intensity was 1,000 lux, whereas at 2,000 lux and dark condition, there was no significant difference between the two media. In addition, these data also show that by using CDA media, conidia density of this fungus was higher in light intensity of 1,000 lux compared to 2,000 lux and dark condition. However, when the fungus was developed in PDA media, the conidium density treated with 1,000 lux was not different with dark condition, but was higher than that with light intensity of 2,000 lux. Overall, it can be stated that conidia density of $V$. tricorpus was higher in CDA media with light intensity of 1,000 lux, whereas the smallest was found at 2,000 lux whatever the medium, and in dark condition the conidia density of $V$. tricorpus was higher in CDA media.

Influence of natural media and its interaction with light intensity are presented in Table 2. This result showed that natural growth media influenced the condia density of $V$. tricorpus. Based on single factor effect, the results showed that the medium of mixture of ground cocoa husk and maize produced significantly higher conidia density compared to other media. On the other hand, growth medium made of cocoa leaves produced the lowest conidia density compared to other media. There was no significant difference among the media of ground maize, ground cacao husk and mixture of ground maize and cocoa leaf in producing conidia. Results of this study showed that there was a synergistic effect between

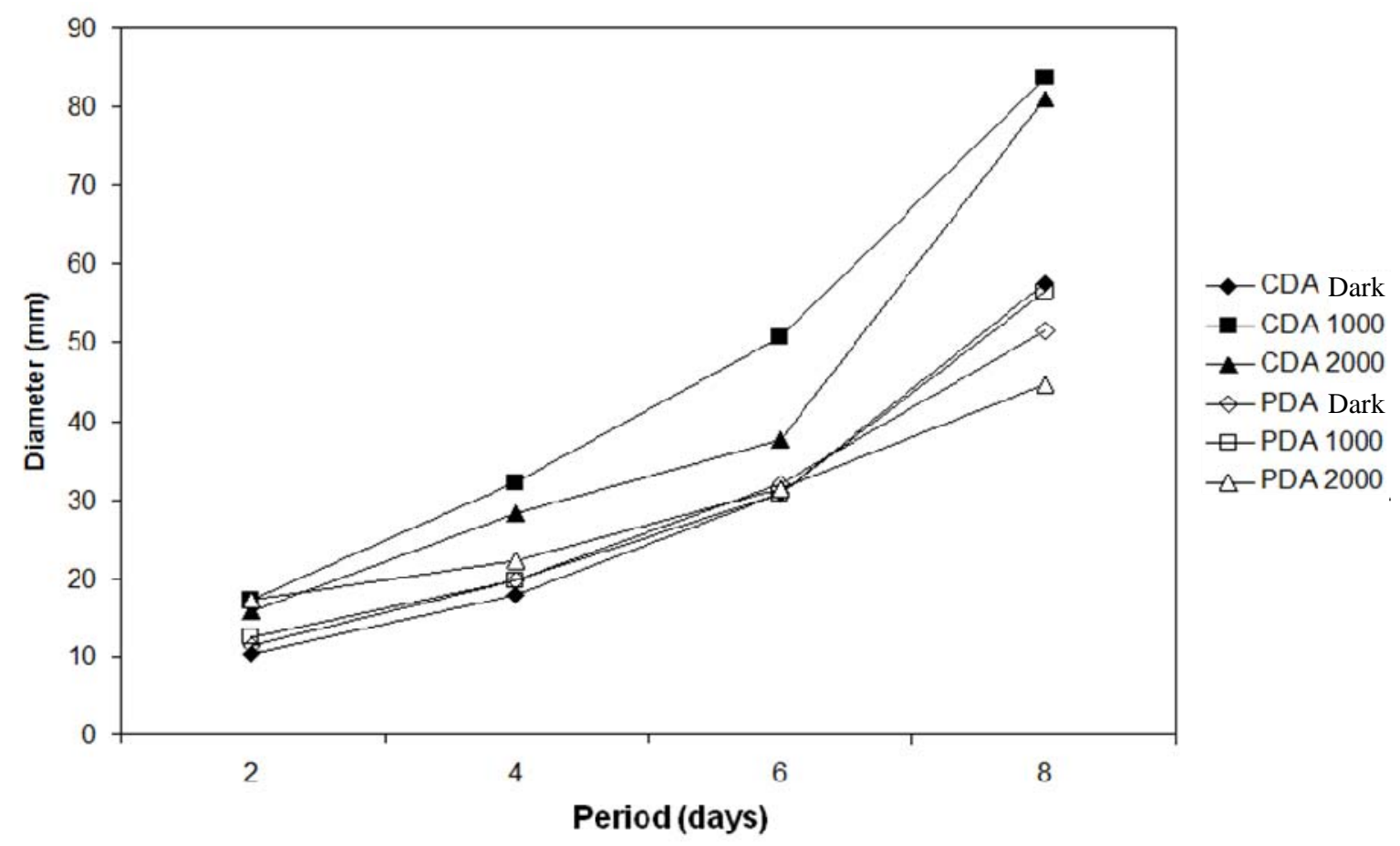

Fig. 1 Vegetative growth of $V$. tricorpus colonies on CDA and PDA media at three light intensities (dark, 1,000 lux and 2,000 lux) during $8 \mathrm{~d}$ observation. 

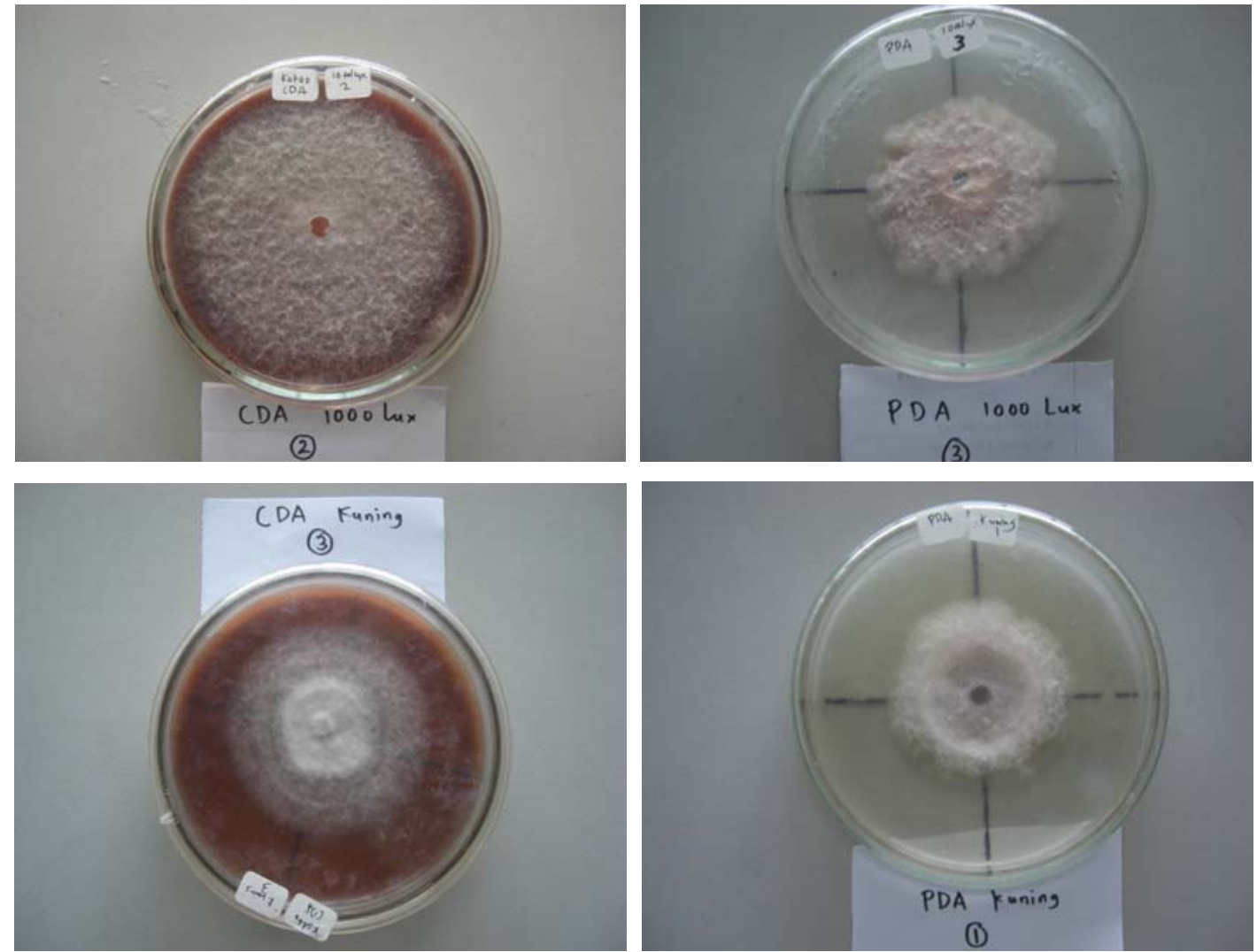

Fig. 2 Colonies of $V$. tricorpus fungus at 8-days-old grown CDA medium (left) and PDA medium (right) at 1,000 lux (top) and under yellow light quality $(500-570 \mathrm{~nm})$ (bottom).

Table 1 Conidia density of 10-days-old V. Tricorpus on CDA and PDA medium with three light intensities (dark, 1,000 lux and 2,000 lux).

\begin{tabular}{lllll}
\multirow{2}{*}{ Medium } & \multicolumn{3}{c}{ Conidia density of $V$. tricorpus $\left(\times 10^{7}\right)$ at diferent light intensity } \\
\cline { 2 - 5 } & Dark & 1,000 lux & 2,000 lux & Mean \\
\hline CDA & $10.37^{\mathrm{aA}}$ & $18.4^{\mathrm{bB}}$ & $11.82^{\mathrm{aA}}$ & $13.53^{\mathrm{a}}$ \\
PDA & $15.35^{\mathrm{aB}}$ & $15.93^{\mathrm{aB}}$ & $10.54^{\mathrm{aA}}$ & $13.94^{\mathrm{a}}$ \\
\hline Mean & $12.86^{\mathrm{A}}$ & $17.16^{\mathrm{B}}$ & $11.18^{\mathrm{A}}$ & \\
\hline
\end{tabular}

Figures in the same column followed by the same small letter or in the same row followed by the same capital letter are not significantly different according to Duncan test at 5\%.

Table 2 Conidia density of 30-days-old fungus $V$. tricorpus grown on natural media under several light intensity.

\begin{tabular}{lllll}
\multirow{2}{*}{ Media } & \multicolumn{3}{c}{ Conidia density of $V$. tricorpus $\left(\times 10^{7}\right)$ at diferent light intensity } \\
\cline { 2 - 4 } & Dark & 1,000 lux & 2,000 lux & Mean \\
\hline Cocoa husk & $5.66^{\mathrm{bB}}$ & $10.35^{\mathrm{bC}}$ & $3.23^{\mathrm{bA}}$ & $6.41^{\mathrm{b}}$ \\
Maize & $6.28^{\mathrm{bB}}$ & $11.08^{\mathrm{bC}}$ & $3.63^{\mathrm{bcA}}$ & $6.99^{\mathrm{b}}$ \\
Cocoa leaf & $1.33^{\mathrm{aA}}$ & $2.96^{\mathrm{aB}}$ & $1.19^{\mathrm{aA}}$ & $1.83^{\mathrm{a}}$ \\
Mixed maize and cocoa husk & $10.23^{\mathrm{CB}}$ & $16.33^{\mathrm{cC}}$ & $7.34^{\mathrm{dA}}$ & $11.30^{\mathrm{c}}$ \\
Mixed maize and cocoa leaf & $6.88^{\mathrm{bB}}$ & $12.32^{\mathrm{bC}}$ & $3.83^{\mathrm{cA}}$ & $7.68^{\mathrm{b}}$ \\
\hline Mean & $6.08^{\mathrm{B}}$ & $10.61^{\mathrm{C}}$ & $3.84^{\mathrm{A}}$ & \\
\hline
\end{tabular}

Figures in the same column followed by the same small letter or in the same row followed by the same capital letter are not significantly different according to Duncan test at 5\%. 
medium of ground maize and ground cocoa husk, because conidia density was significantly higher obtained on mixture of ground maize and ground cocoa husk medium, compared to only ground cocoa husk medium or only ground maize medium. Among several combination media treatments, medium of mixture of ground maize and cocoa husk exposed to light intensity of 1,000 lux resulted the highest conidia density, meanwhile the lowest one was obtained from ground leaf media exposed to light intensity of 2,000 lux or dark condition.

The effect of light intensity is also seen in this experiment as shown in Table 2. Higher conidia density was obtained from light intensity of 1,000 lux compared to 2,000 lux or dark condition. Results of this experiment support previous experiment with artificial media, which showed that fungal growth and development of $V$. tricorpus were suitable at light intensity of 1,000 lux. Nevertheless, in this experiment, the lowest conidium density was found in light intensity of 2,000 lux, whereas in the previous trial the lowest colony development was found in dark condition and only when the medium was CDA.

Effects of light quality and kinds of synthetic media on development of fungal colony diameter of $V$. tricorpus during the first eight days are shown in Fig. 3. The largest colony diameter was obtained when the fungus was grown on CDA medium with light quality as white light. With this kind of growth conditions, the growth rate of the $V$. tricorpus colony can reach 11.1 $\mathrm{mm} / \mathrm{d}$. Meanwhile, the growing conditions with PDA media tended to produce the lowest growth rate as colony diameter reaching only $7.3 \mathrm{~mm} / \mathrm{d}$.

From Table 3, it is noted that there was a significant interaction between synthetic media and the quality of light treatments. Conidia density on CDA media was significantly higher when treated with white light compared to yellow and green lights. On the other hand, on PDA medium, there was no difference in conidia density among the light quality tested. There was no significant difference between CDA and PDA media for white light, meanwhile the conidia density of

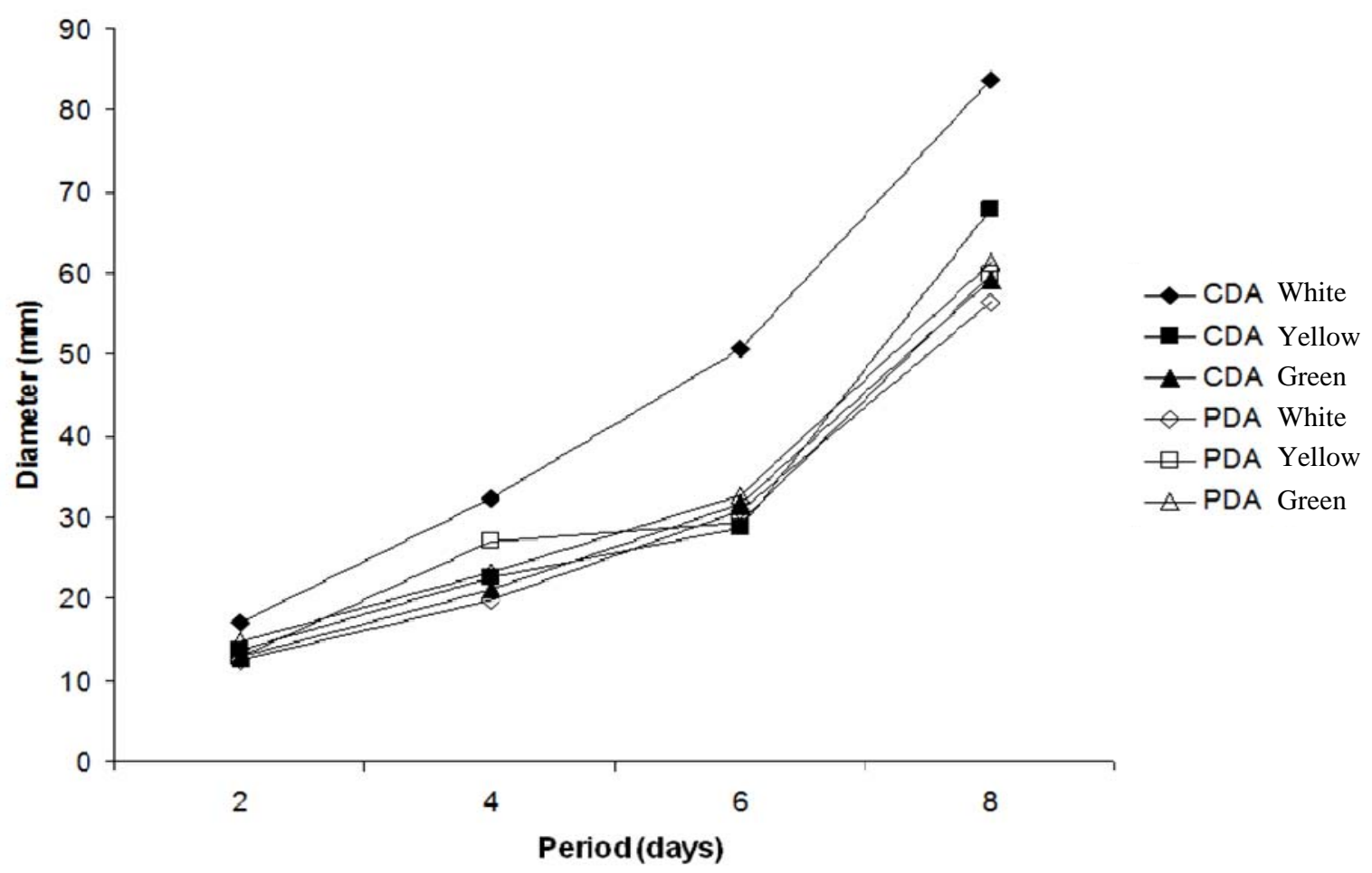

Fig. 3 Diameter development of $V$. tricorpus colonies on CDA and PDA medium at several light qualities during 8 d observation. 
Table 3 Conidia density of 10-days-old fungus V. Tricorpus on CDA and PDA media under different light quality.

\begin{tabular}{lllll}
\hline \multirow{2}{*}{ Media } & \multicolumn{4}{c}{ Conidia density of V. tricorpus $\left(\times 10^{7}\right)$ at diferent light quality } \\
\cline { 2 - 5 } & White & Yellow & Green & Mean \\
\hline CDA & $18.40^{\mathrm{bB}}$ & $11.13^{\mathrm{aA}}$ & $8.97^{\mathrm{aA}}$ & $12.83^{\mathrm{a}}$ \\
PDA & $15.93^{\mathrm{bB}}$ & $18.42^{\mathrm{bB}}$ & $13.56^{\mathrm{bB}}$ & $15.97^{\mathrm{b}}$ \\
\hline Mean & $17.16^{\mathrm{B}}$ & $14.78^{\mathrm{B}}$ & $11.26^{\mathrm{A}}$ & \\
\hline
\end{tabular}

Figures in the same column followed by the same small letter or in the same row followed by the same capital letter are not significantly different according to Duncan test at $5 \%$.

Table 4 Conidia density of 30-days-old $V$. tricorpus at different natural media and light quality.

\begin{tabular}{lllll}
\hline \multirow{2}{*}{ Media } & \multicolumn{4}{c}{ Conidia density of V. tricorpus $\left(\times 10^{7}\right)$ at diferent light quality } \\
\cline { 2 - 5 } & White & Yellow & Green & Mean \\
\hline Cocoa husk & $10.35^{\mathrm{bB}}$ & $14.99^{\mathrm{bC}}$ & $6.02^{\mathrm{bA}}$ & $10.45^{\mathrm{b}}$ \\
Maize & $11.08^{\mathrm{bB}}$ & $15.12^{\mathrm{bC}}$ & $6.68^{\mathrm{bA}}$ & $10.96^{\mathrm{b}}$ \\
Cocoa leaf & $2.96^{\mathrm{aB}}$ & $5.28^{\mathrm{aC}}$ & $1.86^{\mathrm{aA}}$ & $3.37^{\mathrm{a}}$ \\
Mixed maize and cocoa husk & $16.33^{\mathrm{cB}}$ & $18.73^{\mathrm{cC}}$ & $8.09^{\mathrm{bA}}$ & $14.38^{\mathrm{d}}$ \\
Mixed maize and cocoa leaf & $12.32^{\mathrm{bB}}$ & $16.56^{\mathrm{bC}}$ & $6.77^{\mathrm{bA}}$ & $11.88^{\mathrm{c}}$ \\
\hline Mean & $10.61^{\mathrm{B}}$ & $14.14^{\mathrm{C}}$ & $5.88^{\mathrm{A}}$ & \\
\hline
\end{tabular}

Figures in the same column followed by the same small letter or in the same row followed by the same capital letter are not significantly different according to Duncan test at 5\%.

the fungus on PDA medium was higher than on CDA when using yellow and green light. Conidia density on PDA medium with light quality tested was higher than CDA medium, except with white light which showed no significant difference. In general, conidia density on PDA media was higher than on CDA, while in terms of light quality, conidia density was higher in white light, followed by in yellow light and then green light.

Table 4 presents the research results of the effects of natural media and light quality on the conidium density of $V$. tricorpus at $30 \mathrm{~d}$ after inoculation. From these data, it appears that there is an interaction between natural medium and light quality. Mixed medium of ground cocoa husk and maize produced significantly the highest conidia density compared to other media when treated with yellow light. On the other hand, the lowest conidium density was found on ground cocoa leaf when treated with green light. However, based on single factor, media with a mixture of ground maize and cacao husk produced the highest conidia density, followed by mixed media of ground maize and cocoa leaf. When based on light quality, the highest conidia density was found in yellow light treatment, followed by white light. Conidia density at white light treatment was only $75 \%$ compared to yellow light, whereas under green light only $42 \%$. This result is different from the other experiment using synthetic media, which showed that white light was the best when using CDA medium. From the results of this experiment, it showed that highest conidia density was obtained in combination of ground cocoa husk and ground maize medium exposed to yellow light $\left(18.73 \times 10^{7}\right.$ conidia/mL) . Meanwhile, the lowest conidia density obtained in combination treatment of ground cocoa leaf media exposed to green light $\left(1.86 \times 10^{7}\right.$ conidia/mL).

Results of this research have demonstrated that alternative natural media as mixture of ground cocoa husk and maize produced high colony growth rate and conidia density of $V$. tricorpus. On the other hand, the fungal growth based on colony diameter and the sporulation based on conidium density on only ground cocoa husk or only ground maize media were lower compared to the combination of two materials. This shows that there is a synergistic effect between the two materials. In addition, a more positive influence of the addition of the two materials is understandable, 
since mixing the two ingredients may improve nutrition values of the mixed media [21]. This explanation certainly supports the fact that there are specific compounds needed by this fungus present in this medium.

Supply of adequate food is essential to the growth and development of a fungus. A single cell of fungus is composed of cell wall, which has the ability to absorb food. A fungus growing on a complex substrate should change the substrate to nutrients which are more simple before they can be absorbed. To modify the substrate, the fungus will be assisted by enzymes [22], which are capable of being produced by its own. Enzyme is a result of secretion from cells of fungi, which are intracellular (endoenzym) or extracellular (ectoenzym).

The low growth of fungal colonies as well as the fungal development in producing conidia on the media of ground cocoa leaf is more likely associated with low value of nutrients in dry leaves [23]. Nutritional content of fallen plant leaves usually is very low, compared to the still functioning one and leave attached to the plant. According to Mengel et al. [24], the main nutrient elements found in old leaves, such as nitrogen and phosphorus as well as growth regulator and hormones, will be moved to the young plant tissues which are still active. Therefore, in the ground leaf media, the main elements are mainly $\mathrm{Ca}$ and $\mathrm{K}$, which make up the plant cells, while other elements are present in low concentrations.

Results of the study also showed that CDA medium can be used as an alternative artificial medium for growth of $V$. tricorpus in comparison with PDA medium. Study on the role of CDA and PDA as media for multiplication of $V$. tricorpus is still lacking. The results found in this study is interesting, considering that the main component of CDA medium is cocoa derived substances, while in PDA is potato, meanwhile in the mixed ground cocoa husk and maize medium contained also cocoa derived substances. Therefore, there are certain compounds that possibly can be found in that both media, which have positive effects on development of $V$. tricorpus. Meanwhile, Sulistyowati et al. [12] found that Paecilomyces fumusosoceus Pfr-08 isolate grew well on the compacted ground maize medium.

Results of this study demonstrated that fungal colony growth especially on CDA medium reached its optimum condition when using white light with intensity of 1,000 lux. Effects of light on fungal growth can not be generalized [22]. There are some fungi growing well in bright conditions, others are in dark conditions, while several others grow well in diffuse light. Sclerotina sclerotiorum grown on sawn wood medium with low temperature in dark place only produces initials of apotecium, but forms apotecium as soon as the presence of bright light. Many fungi do not depend on light as a necessity for normal development. On the other hand, hymenospora of several fungal species develop abnormally when placed in dark conditions [25]. Results of this study also demonstrated that fungal growth colony of $V$. tricorpus was optimumly achieved when using CDA medium and light intensity of 1,000 lux with white light. However, the results of the present study also showed that the light quality needed for growth and development of this fungus is different. Optimum fungal growth for $V$. tricorpus requires white light with intensity of 1,000 lux, whereas optimum development needs yellow light with intensity of 1,000 lux.

Development of fungus $V$. tricorpus to form conidia is optimum to reach when using yellow light with intensity of 1,000 lux. Light provides good effects to certain fungi in spora germination. According to Jennings [25], ultraviolet light of direct sunlight and very strong light inhibit teliospore germination of Puccinia graminis. When Petri dish covered with green light filter, the spores inside germinate soon. The presence of pigment in spore wall serves as protection to harmful direct light, however, ultraviolet light significantly influences development of fruiting 
bodies of some fungi.

Full development of Colletrothicum lagenarium causing antracnose on pumpkin plant was obtained when cultivating it in Petri dish cultures placed in ultraviolet light. The stimulating effect could occur in protoplast or cell nucleus or can be related with the occurrence of damage of intracellular compounds that affect cell activities. This can also be an expression of a hypothesis that mycelium provided with excessive food may inhibit growth and changes to reproduction phase. The ultraviolet light directed to a fungus can become harmful to the fungus because of its fungicidal effect [22]. Influence of light with different intensities on microorganisms can be manifested through the presence of injure, transformation or specific stimuli.

Safavi et al. [26] showed that the radial growth of fungal strains varied not only with fungal species and isolates but also with the $\mathrm{C} / \mathrm{N}$ ratio of the media used for production of conidia. An isolate of Metarhizium anisopliae showed the highest radial growth in high $\mathrm{C} / \mathrm{N}$ medium, but with low conidial yield. In $B$. bassiana, the low $\mathrm{C} / \mathrm{N}$ medium provided high radial growth of three isolates and high conidial yield of at least two isolates. While, the other strain had the lowest radial growth among $B$. bassiana isolates, but except for in low $\mathrm{C} / \mathrm{N}$, the highest conidial yield maintained in comparison with that of other strains on the similar media. Therefore, colony conidial yield is not definitively correlated with colony growth. High conidial yield was produced in the strains on $35: 1 \mathrm{C} / \mathrm{N}$ medium. Likewise, the highest conidial yield of the mycoherbicide Colletotrichum truncatum was in 30:1 $\mathrm{C} / \mathrm{N}$ medium. In the same way, the maximum yields for two strains of $M$. anisopliae were achieved in a 35:1 C/N medium similar to Sabouraud dextrose agar [27]. Conversely, an isolate of $B$. bassiana produced its maximum spore yield on the low C/N (10:1) medium. Similar results have been produced in some isolates of B. bassiana and M. anisopliae using PDA (C/N ratio 10:1) medium [28, 29]. Also, a liquid medium with $\mathrm{C} / \mathrm{N}$ ratio of $10: 1$ resulted in the maximum sporulation in the entomopathogens $B$. bassiana, M. anisopliae and P. fumosoroseus [30]. Likewise, evaluation of 33 carbon sources on 11 fungal biocontrol agents revealed their role in spore germination, hyphal growth and sporulation [31].

Development of fluffy colonies in high $\mathrm{C} / \mathrm{N}$ medium in two isolates of $B$. bassiana caused fewer conidia to be produced in comparison with other isolate tested, which had smaller radial growth and showed high sporulation in all treatments [26]. In most B. bassiana isolates, colony development in “osmotic stress" medium was fluffy with fewer conidia compared to colonies from high $\mathrm{C} / \mathrm{N}$ medium. In addition, bioassays, conidia production in artificial media, optimal growth temperature, tolerance to solar radiation and production of beauvericin have been considered as good parameters in strain selection research using B. bassiana against plant bugs [32]. Similar with B. bassiana, which have been used as endophytic fungus [33], V. tricorpus also have been investigated as endophytic fungus in biocontrol [17], especially as an entomopathogen of CPB.

\section{Conclusions}

Use of alternative natural media in form of a mixture of ground cocoa pod husk and ground maize provides the best growth and development of $V$. tricorpus. Meanwhile, CDA as semi-synthetic medium was more suitable for the growth and development of $V$. tricorpus compared to PDA.

Semi-synthetic and natural media consisted of ground cocoa husk and/or ground maize are suitable for cocoa production area, where mostly cocoa and corn are planted in lowland area and mostly is also suitable for corn but not for potato growing.

The requirement for light quality was different between growth and development purposes. Development of $V$. tricorpus until the production of conidia in optimal condition was reached when using yellow light with the intensity of 1,000 lux. Growth of 


\section{Growth of Verticillium tricorpus-A Saprophytic Fungus and Potential Entomopathogen of Cocoa Pod Borer as Affected by the Medium and Light}

the fungus colony especially on CDA medium reaches its optimum condition when using white light with the intensity of 1,000 lux.

\section{References}

[1] Sulistyowati, E., Prawoto, A., and Mufrihati, E. 2008. "Technique Development of Integrated Controls of Cocoa Pod Borer (Conopomorpha cramerella)." In Proceedings of 2008 Indonesian Cocoa Symposium. (in Indonesian)

[2] Wiryadiputra, S., Sulistyowati, E., and Prawoto, A. A. 1994. "Technique in Control Long Cocoa Pod Borer, Conopomorpha cramerella (Snell.)." Present at Indonesian Coffee and Cocoa Research Institute Workshop on Controlling CPB Pest in Indonesia. (in Indonesian)

[3] Sulistyowati, and Sulistyowati, E. 1993. "Effect of CPB Pest Attack on Quality of Cocoa Beans.” Warta Puslit Kopi dan Kakao 15: 29-35. (in Indonesian)

[4] Shapiro, L. H., Scheffer, S. J., Maisin, N., Lambert, S., Purun, H., Sulistyowati, E., Vega, F. E., Gende, P., Laup, S., Rosmana, A., Sjam, S., and Hebber, P. K. 2008. "Conopomorpha cramerella (Lepidoptera: Gracillaridae) in the Malay Archipelago: Genetic Signature of a Bottlenecked Population?” Annals of Entomological Society of America 101 (5): 930-8.

[5] Sulistyowati, E., Wardani, S., Wiryadiputra, S., Winarno, H., and Atmawinata, O. 1995. "Effectiveness of Several Pesticides on Cocoa Pod Borer Pest-Conopomorpha cramerella (Snell.).” Pelita Perkebunan 11: 90-105. (in Indonesian)

[6] Susilo, A. W., Mangoendidjojo, W., Witjaksono, Sulistyowati, E., and Mawardi, S. 2009. "Resistant Responses of Several Cocoa (Theobroma cacao L.) Clones toward Cocoa Pod Borer (Conopomorpha cramerella (Snell.)).” Pelita Perkebunan 25: 161-73. (in Indonesian)

[7] Susilo, A. W., Anita-Sari, I., Sobadi, Suwitra, I. K., and Nurlia. 2012. "Stability in Productivity of Promising Cocoa (Theobroma cacao L.) Clones Resistant to Cocoa Pod Borer.” Pelita Perkebunan 28: 123-36. (in Indonesian)

[8] Wijaya, K. A., Prawoto, A. A., and Ihromi, S. 2009. "Induction of Resistance of Cocoa to Cocoa Pod Borer by Application of Silica.” Pelita Perkebunan 25: 184-98. (in Indonesian)

[9] Ho, S. H., Beevor, P. S., and Mumford, J. D. 1987. “A Practical Approach to the Control of the Cocoa Pod Borer Moth Using Synthetic Sex Pheromone in an Integrated System.” In Management of the Cocoa Pod Borer. Kuala Lumpur: Malaysian Plant Protection Society, 53-68.
[10] Sulistyowati, E. 2014. "Effectiveness of Sex Pheromone in Controlling Cocoa Pod Borer-Conopomorpha cramerella (Snell.).” Pelita Perkebunan 30: 115-22. (in Indonesian)

[11] Yuliasmara, F., Firdaus, F., Sulistyowati, E., and Prawoto, A. A. 2010. "Effectiveness of Several Phytocoater Formulas to Protect Cocoa Pods from the Attack of Cocoa Pod Borer.” Pelita Perkebunan 26: 128-39. (in Indonesian)

[12] Sulistyowati, E., Junianto, Y. D., Mufrihati, E., and Wahab, A. 2002. "Effectiveness of a Fungus-Paecilomyces fumosoroseus in Controlling Cocoa Pod Borer-Conopomorpha cramerella." Pelita Perkebunan 18: 31-41. (in Indonesian)

[13] Junianto, Y. D., and Sulistyowati, E. 2000. "Production and Application of Fungus, Beauveria bassiana (Deuteromycotina, Hyphomycetes) to Control Cocoa Myrids (Helopeltis spp.) and Cocoa Pod Borer (Conopomorpha cramerella).” In Proceedings of 2000 Indonesian Coffee and Cocoa Research Institute Cocoa Symposium. (in Indonesian)

[14] Santoso, D., Chaidamsari, T., Wiryadiputra, S., and Maagd, R. A. 2004. "Activity of Bacillus thuringiensis Toxins against Cocoa Pod Borer Larvae.” Pest Management Science 60 (8): 735-8.

[15] Senewe, R., Wagiman, F. X., and Wiryadiputra, S. 2013. "Effectiveness Level of Bio-Insecticide Formulation of Bacillus thuringiensis on Cocoa Pod Borer in Field Condition.” Pelita Perkebunan 29: 108-19. (in Indonesian)

[16] Seidl, M. F., Faino, L., Xiaoqian, S. K., Van Den Berg, G. C. M., Bolton, M. D., and Thomma, B. P. H. J. 2015. “The Genome of the Saprophytic Fungus Verticillium tricorpus Reveals a Complex Effector Repertoire Resembling that of Its Pathogenic Relatives.” Molecular Plant-Microbe Interactions 28 (3): 362-73.

[17] Tyvaert, L., França, S. C., Debode, J., and Höfte, M. 2014. "Biological Control of Verticillium Wilt in Cauliflower by the Native Endophyte Verticillium tricorpus." In Proceedings of the 11th Conference of the Europen Foundation for Plant Pathology.

[18] Prayogo, S., and Yusmani. 2005. "Exposed Period Influence of Sun Light on Viability of an Entomopatogen Fungus-Verticillium lecanii.” Jurnal Habitat Fakultas Pertanian 16 (2): 86-91. (in Indonesian)

[19] Warcup, J. H. 1960. "Methods for Isolation and Estimation of Activity of Fungi in Soil." In Ecology of Soil Fungi, edited by Parkinson, D., and Waid, J. Liverpool: University of Liverpool Press, 3-21.

[20] Gomez, K. A., and Gomez, A. A. 1995. Statistical Procedures for Agricultural Researches. Translated by Sjamsuddin, Baharsjah, E. J. S., and Nasution, A. H. Jakarta: UI Press. (in Indonesian) 

Cocoa Pod Borer as Affected by the Medium and Light

[21] Senthamizhlselvan, P., Sujeetha, J. A. R. P., and Jeyalakshmi, C. 2010. "Growth, Sporulation and Biomass Production of Native Entomopathogenic Fungal Isolates on a Suitable Medium.” Journal of Biopesticides 3 (2): 466-9.

[22] Kavanagh, K. 2011. Fungi: Biology and Applications. Chichester, UK: John Wiley \& Sons, Ltd..

[23] Nasaruddin, Y. M., and Kuruseng, M. A. 2006. "Activities of Several Physiological Processes of Young Cocoa Trees under Various Artificial Shades in Field.” Jurnal Agrisistem 2: 26-33. (in Indonesian)

[24] Mengel, K., Kirkby, E. A., Kosegarten, H., and Appel, T. 2001. Principles of Plant Nutrition. Dordrecht, The Netherlands: Kluwer Academic Publishing.

[25] Jennings, D. H. 2009. The Physiology of Fungal Nutrition. Cambridge, UK: Cambridge University Press.

[26] Safavi, S. A., Farooq, A. S., Pakdel, A. K., Rasoulian, G. R., Bandani, A. R., and Butt, T. M. 2007. "Effect of Nutrition on Growth and Virulence of the Entomopathogenic Fungus Beauveria bassiana.” FEMS Microbiology Letters 270 (1): 116-23.

[27] Shah, F. A., Wang, C. S., and Butt, T. M. 2005. "Nutrition Influences Growth and Virulence of the Insect-Pathogenic Fungus Metarhizium anisopliae.” FEMS Microbiology Letters 251 (2): 259-66.

[28] Wyss, G. S., Charudattan, R., and De Valerio, J. T. 2001.
"Evaluation of Agar and Grain Media for Mass Production of Conidia of Dactylaria higginsii." Plant Disease 85 (11): 1165-70.

[29] Kamp, A. M., and Bidochka, M. J. 2002. "Conidium Production by Insect Pathogenic Fungi on Commercially Viable Agars.” Letters of Applied Microbiology 35 (1): 74-7.

[30] Vega, F. E., Jackson, M. A., Mercadier, G., and Poprawski, T. J. 2003. “The Impact of Nutrition on Spore Yields for Various Fungal Entomopathogens in Liquid Culture." World Journal of Microbiology and Biotechnology 19 (4): 363-8.

[31] Sun, M. H., and Liu, X. Z. 2006. "Carbon Requirements of Some Entomopathogenic and Mycoparasitic Hyphomycetes as Fungal Biocontrol Agents.” Mycopathology 161 (5): 295-305.

[32] Leland, J. E., McGuire, M. R., Grace, J. A., Jaronski, S. T., Ulloa, M., Park, Y. H., and Plattner, R. D. 2005. "Strain Selection of a Fungal Entomopathogen-Beauveria bassiana, for Control of Plant Bugs (Lugus spp.) (Heteroptera: Miridae).” Biological Control 35 (2): 104-14.

[33] Parsa, S., Ortiz, V., and Vega, F. E. 2013. "Establishing Fungal Entomopathogens as Endophytes: Towards Endophytic Biological Control.” Journal of Visualized Experiments 74: e5063. 